\title{
Offensive and Defensive Corporate Entrepreneurship: Learning to Think Like an Outsider
}

\author{
Prescott C. Ensign \\ Schlegel Centre for Entrepreneurship \& Social Innovation \\ Lazaridis School of Business and Economics \\ Wilfrid Laurier University, 75 University Ave West \\ Waterloo, Ontario N2L 3C5, Canada \\ ensign@wlu.ca \\ Nicholas P. Robinson \\ Faculty of Law, McGill University \\ Montréal, Québec, Canada
}

\begin{abstract}
This conceptual study describes an approach to corporate entrepreneurship using an outsider perspective - learning to think like an outsider. Three propositions using this perspective are examined in the context of offensive and defensive corporate entrepreneurship. The impact of market conditions on entrepreneurship are used as a basis for developing these propositions. Finally, we investigate the factors that have a significant impact on the success of entrepreneurial efforts by the firm. These variables include: processes, values, resources, organizational structure, corporate culture, and leadership. We use examples of how mature corporations have responded, with particular attention to the changes confronted by Research In Motion (RIM).
\end{abstract}

Keywords: Corporate entrepreneurship; intrapreneurship; continuous innovation; organizational renewal; disruptive change.

"In spite of a growing body of knowledge on the importance of innovation and change, firms still experience great difficulties in being continuously entrepreneurial."

— Lassen and Nielsen (2009, p. 181)

\footnotetext{
This is an Open Access article published by World Scientific Publishing Company. It is distributed under the terms of the Creative Commons Attribution 4.0 (CC-BY) License. Further distribution of this work is permitted, provided the original work is properly cited.
} 


\section{INTRODUCTION}

In today's global environment, innovation is generally viewed as a way for corporations to survive (Kuratko and Audretsch, 2013). But mature corporations have often viewed innovation as the responsibility of the $R \& D$ department. Point of fact, however, innovation is the lifeblood of a dynamic corporation. Innovation should characterize the total corporation. As Bill Aulet, managing director of MIT's entrepreneurship center, stated: "For big companies to thrive and succeed, they need to be innovative-they all know it, but nobody has really cracked the code yet." The article concluded that Parker Hannifin, "let a maverick engineering boss unleash his own brand of Silicon Valley startup culture" (Forbes, 2015, p. 85). This is the epitome of corporate entrepreneurship in action.

The focus of this paper is on the efforts made by a corporation for survival and growth. The primary emphasis is on innovation - viewed as the key to achieving those goals. Ideally, corporate entrepreneurship involves managers and subordinates communicating, negotiating, and taking action. It is an "interactive and recursive process in which structures and managerial initiatives affect individual behavior, and individual behavior affects structures and management behavior" (Heinonen and Toivonen, 2007, p. 165).

A corporation's efforts to cope with market forces may be described as offensive corporate entrepreneurship and defensive entrepreneurship. In this study offensive corporate entrepreneurship describes those efforts aimed at continuous innovation. The focus is on self-renewal efforts aimed at meeting the firm's goals of growth and financial success. Defensive corporate entrepreneurship is used to describe those efforts made to combat or overcome organizational inertia that threaten the firm's survival. The challenges of maintaining a proactive mindset become increasingly difficult as a firm grows and matures.

Entrepreneurship has been associated with certain environmental circumstances (Kurtatko et al., 2015). Market hostility has often been associated with corporate entrepreneurship and other forms of innovation. Limited labor market opportunities have been associated with immigrant and minority entrepreneurship. Individual entrepreneurs often emerge from outside of established segments of society. Scholars have documented the propensity for numerous so-called outsider groups to engage in entrepreneurial activity (Kelmar, 1994; Ley, 2006). But the entrepreneur's status as an outsider is often viewed as an opportunity. The pressures faced by immigrant, minority, and other outsider groups have transformed them into 
innovators (Coven et al., 2000). The drive to survive - not the desire for stability - led to this phenomenon.

Queuing off the reasons an outsider chooses entrepreneurship, we describe an approach to corporate entrepreneurship using the term outsider perspective - learning to think like an outsider. In this study we propose that a mature corporation may do well to understand and use this perspective. The conceptual framework of this study is based on three overarching propositions.

Proposition 1: Corporate entrepreneurship - both offensive and defensive - will benefit from taking an outsider perspective.

Proposition 2: An outsider perspective is easier to embrace when the company is experiencing financial difficulties and success is threatened, requiring defensive corporate entrepreneurship.

Proposition 3: An outsider perspective is harder to embrace when the corporation is profitable and experiencing success, utilizing offensive corporate entrepreneurship.

Our investigation seeks to answer a number of questions about the outsider perspective as it relates to offensive and defensive corporate entrepreneurship. What is the outsider perspective? Why is this perspective needed? What conditions impact a firm's success in using this perspective? We conclude that both kinds of corporate entrepreneurship — offensive and defensive - will benefit from taking an outsider perspective. An outsider perspective may be the key to being continuously entrepreneurial for sustained growth and profitability.

\section{Corporate Entrepreneurship: Confronting Challenges}

The terms corporate and entrepreneurship would seem to be opposites. The term corporate implies static structures, bureaucracy, and an ordered collective. The term entrepreneurship elicits images of new concepts, creative approaches, informal organizational structures, solutions that defy the odds, and new venture creation (Timmons et al., 2010). So what is the result when these are combined? Corporate entrepreneurship requires that some of the elements that make mature enterprises such prolific vehicles for the delivery of goods and services need to be changed. Corporate entrepreneurship poses an incredible challenge to managers and employees who must rethink their processes, values, and even resources in order to achieve success. Examples of successful corporate entrepreneurship suggest that 
innovation is easier to accomplish when specific efforts are separated from the established corporation, by a Chinese wall or even an arm's length subsidiary (Evald and Senderovitz, 2013). The greater the distance from existing institutions and norms the lower the threat of interference. By definition, entrepreneurship demands that the corporation will need to make changes, at least to some degree, in existing processes, values, and resources.

While many mature corporations have difficulty accepting slimmer profit margins, individual entrepreneurs are less risk averse and pursue opportunities without regard to the resources under their control (Timmons et al., 2010). Entrepreneurial corporations are those that have mastered the ability to identify new opportunities, are proactive innovators, and less risk averse (Lumpkin and Dess, 1996). Risk taking, autonomy, innovativeness, proactiveness, and competitive aggressiveness have all been associated with entrepreneurship (Covin and Miles, 1999). Some authors see innovation as the defining characteristic of all entrepreneurial efforts. Others include all "non-routine activities by those who direct economic activities," irrespective of whether a private individual or a mature corporation is implicated (Baumol, 1993, p. 8). According to Zahra and Covin (1995, p. 45), corporate entrepreneurship is a reflection of a "company's commitment to innovation in an existing business."

Once a firm matures and becomes too comfortable in its market space it begins to lose the same survival skills that led to its initial growth and enabled it to remain at the cutting edge of innovation (Weiblen and Chesbrough, 2015). By definition, a mature corporation has developed processes, values, and resources that are fundamental to its current business model. It has difficulty coping with changes and challenges to these elements (Lassen and Nielsen, 2009). In times of market turmoil and disruptive change the processes, values, and resources that were essential in maintaining a stable market position may become the company's greatest weaknesses (Penrose, 1959/1995).

Under these circumstances the mature corporation is hampered by its inability to change and struggles to adapt. The company's position as an established business is of no help. The firm is forced to assess its goals, question its structures, and examine its choices. An entrepreneurial spirit the same spirit that drives individual entrepreneurs to accept low profit margins and uncertain outcomes - necessitates movement away from corporate bureaucracy in favor of fluid structures that enable experimentation, risk-taking, and alternative modes of thinking and working. Like the individual entrepreneur who tolerates the uncertainty of success in its 
market, mature corporations that seek to survive and grow must abandon institutions and norms that impede success in favor of whatever works (Gilbert, 2003). In other words, firms that wish to engage in corporate entrepreneurship must be able to change processes, values, and resources in favor of those that are better suited to its competitive environment.

Entrepreneurship calls for moving away from the bureaucracy that is embedded in the corporation and moving toward the "fluidity" that is present in all forms of entrepreneurial activity (Burgelman, 1983, p. 1362). The firm's business model can inhibit its ability to recognize and seize new opportunities (Tang and Rothenberg, 2009). Empirical evidence from Chowdhury (2005) demonstrates this very point - that corporations are most likely to succeed in an entrepreneurial endeavor when the groups involved are receptive to diverse ideas. We suggest that individuals in those groups must learn to think like an outsider. Corporations must be willing to examine and change processes, values, and resources to be receptive to diverse ideas. They must find ways to ensure that established patterns of operation do not interfere with its analysis of new business opportunities or hinder the firm's entrepreneurial processes (Fillis and Rentschler, 2010). Strict adherence to a firm's processes, values, and resources can be a barrier to thinking outside the box.

\section{Corporate Entrepreneurship - Learning to Think Like an Outsider}

The business community views an individual entrepreneur as a person who possesses the character, courage, and vision to depart from accepted routines and practices (Baumol, 1993, p. 8). The departure from accepted routines and practices by an individual is perhaps the most challenging part of undertaking entrepreneurial activities for the mature corporation. Scholars generally agree that mature corporations engage in more intense entrepreneurial efforts when facing hostile market conditions (defensive corporate entrepreneurship). At that point they may also be more successful in achieving innovation. The question then is: how do mature corporations engage in significant entrepreneurial efforts when market conditions are stable (offensive corporate entrepreneurship)? Could they then become more successful innovators?

Offensive corporate entrepreneurship is just as important as defensive corporate entrepreneurship. A good defense is not a substitute for a good offense. Continuous innovation is needed for growth and survival in today's global environment. We argue in support of the premise put forward by Zahra (1991) and Gaw and Lui (2004) that both offensive and defensive 
corporate entrepreneurship will occur if the mature firm chooses to challenge its established processes, values, and resources by giving entrepreneurial teams the freedom and flexibility needed to innovate.

How can this be accomplished? We propose that a firm's entrepreneurial efforts can benefit from taking an outsider perspective - learning to think like an outsider.

\section{Proposition 1: Corporate entrepreneurship - both offensive and defensive - can benefit from taking an outsider perspective.}

This approach - taking an outsider perspective - is a concept that can provide the mature corporation with a way to understand entrepreneurial efforts in a mature corporation. But what can go wrong? Unfortunately an established corporation has strategies and structures that support in-the-box thinking rather than thinking like an outsider (Kuratko et al., 2014). Even extrapolation and prediction of the future may not result in new approaches and new thinking. Unless a crisis is perceived or acknowledged, the perception may be that it does not exist. Getting to a mindset of urgency is difficult, especially if it does not seem likely. Something pressing may be necessary to arrive at new ways of thinking.

So where does this leave the corporation? In this paper we use examples from Research In Motion (RIM) - creators of the BlackBerry - to assess general responses to innovation and entrepreneurship. Based on the lead author's location in Waterloo (headquarters of $\mathrm{RIM}^{1}$ ), we have followed the story and assessed the issues raised at RIM (cf. Ensign and Robinson, 2008). CNET (2011) ran a headline "How RIM intends to light a fire under developers." It was suggested that CEO Heins should issue the ultimatum: work like your job depends on it, because it does. Tech veteran David Strom (2011) goes so far as to suggest that if "internal morale is compliant but not inspired; you need to light a fire." Outspoken critic Vic Alboini told Bloomberg (2012) that RIM needs a sense of urgency in desperate times.

As proposed in this paper, mature corporations can benefit from taking an outsider perspective. A firm that strives for an outsider perspective early in its history - before strategy, structure, and systems have solidified may exhibit higher performance. Once committed to an outsider approach an established firm has a greater likelihood of growth and financial stability. Those firms able to continuously embrace and absorb outsider ideals and

\footnotetext{
${ }^{1}$ Research In Motion Ltd. changed its name to BlackBerry Ltd in 2013.
} 
attitudes may stave off atrophy in competitive positions associated with maturity.

Picking up on the notion of 'lighting a fire' raises several questions. Is something necessary for a mature corporation to arrive at new ways of thinking? Could corporate entrepreneurship occur and succeed if fires (emergencies) are purposefully set? Would the difficulties of manufacturing a fictitious crisis depend on whether the firm has a stable or hostile market environment? These may be interesting ideas to pursue in another research study (cf. Kuratko et al., 2014).

\section{Corporate Entrepreneurship and Its Competitive Environment}

The market environment seems to have an outsized impact on entrepreneurial efforts undertaken by a mature corporation. The propositions presented in this study are based on the differences in a firm's market environment - whether it is stable or hostile. The primary focus of a firm is to provide a product that meets market demands. But we know that markets are based on competition. There is always another player who can enter the market and disrupt or displace the incumbent firm's product. The market accounts for tensions between established and outside enterprises and can remedy deficiencies. The meritocratic workings of the market are an important part of the entrepreneurial process and are related to the market mechanism that values new entrants and their products on the basis of their ability to meet needs.

Companies are generally more willing to reconsider their processes, values, and resources under highly competitive market conditions when the firm's survival is at stake (Kuratko and Audretsch, 2013). Under these conditions the hostile market environment provides the additional impetus needed to seek out innovative new processes and question existing values and resources. The importance of market hostility "stems from the fact that it reflects the extent of environmental support for organizational activities like corporate entrepreneurship" (Zahra and Covin, 1995, p. 45). The corporation is forced to act defensively in order to ensure its survival. Under these conditions, it is more likely to engage in corporate entrepreneurship.

Research conducted by Covin et al. (2000) corroborate Zahra's (1991) arguments. Certain environments are more likely to "encourage or reward the actions" of companies that engage in market pioneering — when a company is the first to "offer a distinctively new product to the market" (Covin et al., 2000, p. 175). Under these conditions firms pioneer a new product in order to create some basis for a sustainable competitive 
advantage (Covin et al., 2000, p. 177). In other words, the corporation engaged in a struggle to survive will attempt to establish a foothold in the market by developing a competitive advantage. Under docile market conditions firms are less compelled to engage in this type of activity. Ferreira (2002, p. 17) concludes that:

Corporate entrepreneurship would seem to depend both on the capabilities of operational level participants to exploit entrepreneurial opportunities and on the perception of corporate management that there is a need for entrepreneurship at the particular moment in its development. From the perspective of top management, corporate entrepreneurship is not likely to be a regular concern, nor an end in itself. Rather, it is a kind of 'insurance' against external disturbances or a 'safety valve' for internal tensions resulting from pressures to create opportunities for growth.

But hostile market conditions may bring about urgency and new ways of thinking. We suggest that corporate entrepreneurship will occur and succeed if previously held views and beliefs are abandoned in favor of an outsider perspective. We argue that both offensive and defensive corporate entrepreneurship are needed in order to cope with a competitive environment.

\section{Defensive Corporate Entrepreneurship - Disruptive Change}

Companies will generally engage in more intense entrepreneurial efforts when facing hostile market conditions (defensive corporate entrepreneurship). In a defensive situation - when a mature firm is faced with market hostility - corporate entrepreneurship takes on a greater role. Scholars conclude that companies are generally more likely to rethink their business models under circumstances that are threatening. Defensive responses, often involving the abandonment of accepted processes, values, and resources, evoke the same survival skills that are used by an individual entrepreneur. A poignant example is RIM. After enjoying tremendous growth and profitability, the market delivered blow after blow to the company. Customers and tech analysts acted as pathologist in explicating the company's demise from a market capitalization of over $\$ 80$ billion in 2008 to less than $\$ 4$ billion in 2012.

In this paper we propose that defensive corporate entrepreneurship can benefit from taking an outsider perspective - learning to think like an outsider. 
Proposition 2: An outsider perspective is easier to embrace when the company is experiencing financial difficulties and success is threatened, requiring defensive corporate entrepreneurship.

It is easier for a mature corporation to reevaluate the status quo when it is confronted with significant threats to its success or survival. For example, the makers of BlackBerry had to make drastic changes because of market turmoil and threats from its competitors - especially the iPhone. The view appeared to be: desperate times call for desperate measures. RIM jettisoned its co-CEOs and numerous executives. It underwent rounds of substantial layoffs in the hopes of generating something new that would resonate with the market - including the promise of the fabled BB10, a proprietary mobile operating system based on QNX. RIM acquired QNX, a microkernel based operating system that parceled out smaller tasks. Despite the layoffs and other measures of austerity, RIM continued to hire in select areas and invest resources in promising technologies — including those that might not be commercialized for a decade or more.

Most of the focus in research studies has been on defensive entrepreneurship, undertaken when facing hostile market conditions. This type of entrepreneurial activity is responsive in nature and often undertaken in order to survive. In a study involving 102 manufacturing companies (Zahra, 1993), environmental hostility was found to be strongly associated with particular manifestations of corporate entrepreneurship such as product development (Zahra and Covin, 1995, p. 48). Gilbert (2003) documented Kodak's attempt to compete against the threat of digital photography by introducing digital photography machines to photo development shops. Hewlett-Packard failed in its attempt to corner the memory market for game consoles. In both of these scenarios, the firms failed to recognize the need for innovation. Each lost sight of the fundamental changes taking place in their respective markets. Each failed to meet changing market conditions and demands.

The processes, values, and resources of a mature corporation can interfere with entrepreneurial efforts designed to fend off market hostility. In the 1970s IBM - a company best known for its mainframe computers concluded that the personal computer market was too small, outside its corporate client base, and the effort would not be worthy of their attention (Engelen, 2002, p. 211). IBM's values (their way of thinking) were an impediment to entering the subsequently enormous and lucrative personal computer market. This is an extraordinary example of how the corporate mindset - rather than an outsider mindset - can interfere with an analysis 
of opportunities. IBM, like numerous other established corporations, simply thought that the new market was outside of the company's scope for products or customers (Gilbert, 2003, p. 27). The point here is that many opportunities emerge beyond the bounds of the company's traditional market and are not served by the established marketing structure. Established processes, values, and resources makes it challenging for a mature corporation to see the threat and the opportunity presented. Adapting those to today's environment will play an important part in entrepreneurial efforts.

According to Gilbert (2003, p. 27), "established players have more time than they think, provided they take off the blinders that keep them from seeing beyond their current customers." One of the reasons it is so difficult for managers in established companies to recognize opportunities is because the new markets lie outside their existing resource bases. It is imperative for mature corporations to explore new opportunities that can meet the needs of a changing market. They need to identify serious market changes by shifting attention away from the established market. This will require an adjustment in the firm's established processes, values, and resources.

Taking an outsider perspective - thinking like an outsider - does mean taking the blinders off. This perspective will help the corporation identify opportunities and solutions to formerly unmet needs. Entrepreneurial efforts can then evaluate how the needs of a new market can be met. The problem presented is this: "established players, which often have trouble seeing the new customer in the first place also find it difficult to conceptualize a new business model that would allow them to serve this new market profitably" (Gilbert, 2003, p. 30). New customers cannot be served in the same way as existing customers. Entrepreneurial efforts need to focus on the customer to succeed in the new market. Examples of how mature corporations entrench themselves, making them incapable of breaking into new markets, are: failure to adapt the business to customer needs, aggressive growth expectations, unwillingness to explore markets that currently have slim margins, and incompatibility of a product with a company's current processes, values, or resources.

Zhu et al. (2006) compare incumbent SMEs and entrepreneurial startups. While existing SMEs wallow in their surroundings, the new venture without a history (without baggage) leaps ahead with little caution. Fueled by a voracious appetite for what it believes to be possible; "entrepreneurial start-ups identify, create, and exploit new opportunities continuously" (Zhu et al., 2006, p. 1). Incumbents who are haunted and hindered by past successes - things that may dictate direction or failures which may make 
them gun-shy - will have difficulty getting out of their own way. They are unable to undertake new opportunities. As Zhu et al. (2006, p. 1) indicate, SMEs are hampered by their reliance on the capabilities that exist in their embedded networks. While learning is vital, it can also lead to the establishment of bad habits (attitudes, routines, and processes) that result in opportunities dismissed. As we have proposed taking an outsider perspective which requires thinking like an outsider is imperative in these situations.

A move away from the established corporate governance structure toward a focus on corporate entrepreneurship will allow entrepreneurial teams to establish a meritocracy, one that differs from corporate norms and moves toward meeting consumer needs (Robinson and Ensign, 2010). In examining ownership structure, Pittino and Visintin (2009, p. 269) find that the pursuit of radical innovation strategies is related to the presence of persons from outside the corporation. These firms are more likely to be 'prospectors' in the Miles and Snow typology. For example, as part of RIM's reorganization, many called for greater change in the board of directors.

\section{Offensive Corporate Entrepreneurship - Continuous Innovation}

Can companies with stable non-hostile market conditions have an entrepreneurial focus (offensive corporate entrepreneurship)? Will they become more successful innovators? We argue in support of the premise forwarded by Zahra (1991) and Gaw and Lui (2004) that both offensive and defensive corporate entrepreneurship can occur if the mature firm chooses to challenge its established processes, values, and resources by giving entrepreneurial teams the freedom and flexibility needed to innovate.

The fact that corporate entrepreneurship more frequently occurs as a response to the market rather than as a part of a concerted effort to improve corporate performance illustrates the failure of the modern corporation to engage in offensive entrepreneurship. Rather than waiting for the market to resolve the friction between established firms and newcomers, corporations should be proactive and seek out new ways to improve their products, processes, and values in order to engage new markets and satisfy consumer needs. Entrepreneurship does not have to be defensive in nature. Corporations that are receptive to new ideas and open to changing processes, reconfiguring resources, and valuing innovation can evade the problems associated with being a market follower and become a market pioneer.

In a mature market, the established corporation often has difficulty initiating entrepreneurial endeavors proactively (Covin and Slevin, 2002). As 
they become increasingly comfortable in their market space they become more efficient, making it even more difficult to compete. By then, "the very nature and structure of the modern corporation is centered on increasing the efficiency of performing specific functional tasks and not on innovation" (Gaw and Lui, 2004, p. 69). Offensive corporate entrepreneurship requires the company to think and act like it would in a defensive scenario by experimenting with new processes, values, and resources. But Covin and Slevin (2002) indicate that the degree of impetus provided by the threat posed in a defensive scenario cannot be entirely replicated in an offensive situation.

The challenge with offensive corporate entrepreneurship is that "the riskaverse culture of traditional corporations stifles opportunities for innovation" (Gaw and Lui, 2004, p. 67). Reliance on the corporation's processes, values, and resource bases can make it an impotent competitor in hostile markets and stifle corporate entrepreneurship in docile markets. The firm will need to consider channeling some of its efforts in new ways and sometimes in new directions. It needs to consider changes to the status quo in order to meet new opportunities. The mature corporation has some positive advantages: it has "access to the firm's market and industry experience" as well as its resources (Gaw and Lui, 2004, p. 67).

Offensive corporate entrepreneurship implies continuous entrepreneurial efforts. In this study we propose that these efforts can benefit from taking an outsider perspective - learning to think like an outsider.

Proposition 3: An outsider perspective is harder to embrace when the corporation is profitable and experiencing success, utilizing offensive corporate entrepreneurship.

As this proposition suggests, taking an outsider perspective is more difficult when the firm is experiencing profitability and success. The easier path is to 'stick with what we know' rather than take a chance on something new. Taking an outsider perspective - learning to think like an outsider will enable a firm to renew, refresh, grow, and remain viable. Studies of corporate entrepreneurial teams validate this claim.

Offensive corporate entrepreneurship has the disadvantage of taking place when market hostility is absent - what supported the innovative efforts - and this same urgency cannot be entirely replicated (Kuratko et $a l ., 2014)$. But can this urgency be staged by starting a 'fire' under a team or department? Would this be dismissed as just 'crying wolf'? Perhaps further study could determine if this hostility can be replicated. 
Most of a corporation's entrepreneurial efforts are characterized by the use of teams to undertake these efforts. (Chowdhury, 2005, p. 728) concludes that "effective entrepreneurial teams are those that have high member commitment and develop a process that uses diverse perspectives on problems, a variety of potential solutions, and a variety of criteria for evaluating solutions to make complex and innovative decisions." This openness to different perspectives and a high level of motivation in a team are the traditional characteristics we see when individual entrepreneurs are involved in a new venture. Enabling different perspectives from different team members cannot be underestimated. Any widespread acceptance of the firm's processes, values, and resources, however, will interfere in the sharing of diverse ideas advocated by Chowdhury (2005).

That said, the creation of some team-specific fixed structure is needed to insure that diverse ideas are shared. This means developing a "system of team interaction that not only would ensure that each member proposed different approaches, points of view, alternatives, etc., but would also encourage members to compare diverse alternatives and approaches and weigh them against each other" (Chowdhury, 2005, p. 728). Entrepreneurial teams that develop their own "well-articulated values (centering on the employees as individuals and competition)" stand an improved chance of success in offensive corporate entrepreneurship (Zahra, 1991, p. 277). Both Chowdhury (2005) and Zahra (1991) suggest that the creation of a new structure is beneficial, providing it is not simply the corporation's structure superimposed onto a new one. What this means is that the entrepreneurial team needs to be insulated from the larger corporation and allowed to develop its own processes, values, and resources tailored to the needs of the market.

\section{Corporate Entrepreneurship - Factors that Impact Success}

Opposing forces are identified as "essential to successful corporate entrepreneurship, but set very different agendas" (Lassen and Nielsen, 2009, p. 181). Tensions are inevitable; they need to be embraced not avoided. Continuous and balanced efforts rather than punctuated efforts are performance enhancing. These will build on the exploration/exploitation forces described by March (1995). Corporate entrepreneurship will occur and succeed in a mature company when it is able to examine or even relinquish some of its established processes, values, and resources. This will allow the firm to direct energy and resources to new considerations. 
Corporate entrepreneurship requires a level of adaptability that mature firms have difficulty achieving. As stated earlier, firms are generally more entrepreneurial in defensive situations when market conditions require a response. Under these conditions competitive intensity is at its highest, exacerbated by price wars, low customer loyalty, slim profit margins, and high failure rates (Covin et al., 2000, p. 179). There is a greater likelihood that corporate entrepreneurship will take place because survival is at stake: desperation serves as an impetus for innovation (Stopford, 1994). Corporations facing these circumstances are more apt to modify their processes, values, and resources to meet the market's demands. Hostile conditions make corporate entrepreneurship almost inevitable. Since a firm's processes, values, and resources define what a corporation can and cannot do, adaptation necessitates reevaluating the status quo. A change is needed. What is needed to succeed in the marketplace? We suggest that learning to think like an outsider is the challenge for companies that wish to act entrepreneurially.

Simply assuming that a potential entrepreneurial effort does not fit with the firm's current processes, values, and resources will severely restrict what the firm thinks it can do. This makes corporate entrepreneurship much more difficult. Table 1 summarizes the forces suppressing corporate entrepreneurship.

Processes by their very nature are "set up so that employees perform tasks in a consistent way, time after time" (Christensen and Overdorf, 2000, p. 68). Given that processes are not meant "to change or, if they must change, to change through tightly controlled procedures," the challenge is

Table 1. Elements Limiting Corporate Entrepreneurship.

Processes The inability to deliver a new product to a new customer using existing processes; failure to adapt or create alternative processes to accommodate a new customer or market; dismissal of new organizational structures (such as entrepreneurial teams, communities of practice, or spinoffs).

Values Corporate mores and cultural norms stressing a particular level of profitability; values that dictate only markets of a certain size are worth attention; rejection of ideas that differ from core corporate ideals.

Resources Inappropriate or insufficient resources; hesitance to explore using new suppliers or inputs (such as human capital); improper coordination of resources due to process failures; resource overload (difficulty managing extensive resource bases). 
to develop an entirely new process that meets the demands of a particular situation (Christensen and Overdorf, 2000, p. 68). This is precisely why an organization's processes are where the "organization's most serious disabilities in coping with change reside" (Christensen and Overdorf, 2000, p. 69). For example, companies moving from a mass production model to a customization product design model would need to design completely new processes to satisfy demands in discrete and unique markets. New thinking is required to accomplish these changes. Hartopo (2012) states that RIM's demise is not just due to "the rise of its rivals but the failure to properly recognize and rally to the changes involved in consumer demand."

Values influence a firm's ability to engage in corporate entrepreneurship. Significant entrepreneurship occurs when these efforts become an important shared value (Sathe, 2006), especially when the corporation is under threat. Corporations seem most prone to innovating their processes, values, and resources under these circumstances. Firms with fixed values that do not meet the market's needs are phased out while firms that successfully adapt their processes, values, and resources and engage in entrepreneurial endeavor survive (Ozgen and Baron, 2007).

Consistent, broadly understood values define where an organization can navigate and influence how it perceives opportunities and threats. Values which dictate that only high profit projects be undertaken may deter firms from pursuing certain opportunities. IBM's initial failure to consider the seemingly low-profit personal computer market is a good example of this. Values that stress a continuation of what fits with what we do can pose a barrier to finding the right people needed to succeed. Having the right set of values for the right project is essential for success (Tang and Rothenberg, 2009). Values evolve and become more conservative, risk averse, and less dynamic as a firm transforms into a mature corporation (Lassen and Nielsen, 2009). Jason Eckert, Dean of Technology at triOS College, describes RIM as having the "worst corporate culture in the world." In Hicks (2012) view, “The company's earlier rapid growth had meant hiring a layer of lifelong managers, many of them risk-averse. Fiefdoms were carved out and protected; a degree of complacency settled in.... The environment inhibited new ideas; instead of daring to be bold... employees worked in fear."

Resources - their abundance or lack thereof - have a significant influence on corporate entrepreneurship. If there is a perception that resources are lacking, conservative thinking takes the place of thinking like an outsider. There is too much risk in entering a new market: the opportunity should not be explored. For that reason, corporate entrepreneurship 
often takes place outside the scope of the existing firm's business model (Fillis and Rentschler, 2010). The other side of this is that failing to leverage resources, beyond the firm's conventional approach, may drastically restrict opportunities for corporate entrepreneurship. The firm must find ways to gain access to the people, ideas, and resource inputs necessary to engage a new opportunity.

Organizational structure has a significant impact on entrepreneurial efforts (Garrett and Covin, 2015). At times the corporation must adopt a structure that insulates entrepreneurial efforts from existing processes, values, and resources. The issue of control must be addressed: it can have a significant impact on the success of an entrepreneurial effort. Zahra (1991, p. 277) suggests that control has often been "negatively associated with both internal and external corporate entrepreneurship activities." Increased control adds "rigidity to the structure, thereby stifling initiative and, ultimately, corporate entrepreneurship" (Zahra, 1991, p. 277). Top-down management structures within the entrepreneurial team or emanating from outside the entrepreneurial team can be suppressive. This is particularly problematic when the entrepreneurial team is contained within the existing organization, referred to as intrapreneurship by Stopford (1994). This can make it more difficult for the team members to evade the corporate controls that they are attempting to escape. Steve Jobs reportedly indicated that his most important task at Apple was to act as a giant umbrella shielding his designers from corporate controls. Taylor (2001, p. 129) strongly advocates decentralized structures and corporate spin-offs in order to ensure that entrepreneurial teams have the power and resources necessary to "enable them to operate entrepreneurially." Radical decentralization has been a "vital factor" in the entrepreneurial success of some companies. To be successful, entrepreneurs must develop their own processes and values as well as choose their own resources.

In order to facilitate the sharing of ideas and diverse perspectives an entrepreneurial team must establish an environment of trust and loyalty for improving team commitment (Chowdhury, 2005). Trust is a key element in knowledge sharing between individuals within an organizational setting. Trust encourages increased knowledge sharing, results in lower transaction costs, and ultimately stimulates the process of innovation (Ensign, 2009).

Subsidiary companies and spin-offs tend to be the best insulated from head-office interference and the established corporate culture (Turró et al., 2014). Taylor (2001) concludes that such structures are often superior to internal corporate teams that must cope with the internal corporate culture while trying to develop their own autonomous culture suited to the task at 
hand. As a general rule, the greater the distance from the established firm's processes and values and the greater the voluntary access to resources, the higher the likelihood of entrepreneurial success. Freedom begets creativity and produces an atmosphere conducive to identifying and seizing opportunities. There seems to be agreement on two issues: corporate entrepreneurship demands a review of the governance structure of an established firm; and distance or isolation from the corporate core may be necessary for an entrepreneurial genesis to take hold and gather momentum (Evald and Senderovitz, 2013).

The incorporation of general corporate objectives, for instance to develop a product for a particular market niche, is acceptable provided that those entrepreneurial teams that diverge from this path and stumble upon something else are also respected. Experimentation is an important and common element of the innovating process and cannot be limited. Pfizer was developing a drug to treat angina, when it was discovered that Viagra was better suited to treat erectile dysfunction.

Corporate culture has had a long history in the business literature. Numerous empirical studies have examined the impact of corporate culture on entrepreneurship (Turró et al., 2014). But these studies have presented differing opinions. Some fail to see the ultimate contradiction between having broadly understood company-wide values and stimulating corporate entrepreneurship. For example, Taylor (2001, p. 146) argues for the "creation of a strong corporate culture with clear values and stretch goals." Gilbert (2003) suggests that an overpowering corporate culture can devastate corporate entrepreneurship. Taylor's advocacy of a strong corporate culture would damage the ability of the entrepreneurial team to act innovatively. Our conclusions are: corporate culture does play a significant role in the success or failure of entrepreneurial efforts; and a strong corporate culture that values entrepreneurship does need accountability, review of performance, and commitment to shared goals.

Taylor (2001) and Miller (1983) indicate that top management support is important in providing access to resources. Both assert that corporate entrepreneurship requires the support of the board of directors and senior management. Interference with the culture or values of the entrepreneurial team can mitigate the independence created by providing access to resources and the freedom to develop new processes (Garrett and Covin, 2015). Christensen and Overdorf (2000, p. 74) concur: "only the CEO can ensure that the new organization gets the required resources and is free to create processes and values that are appropriate to the new challenge." Scallan (2012) has a statement that seems on target. "RIM's challenge to 
new hires. Transform company. Resist internal corporate culture." But as we saw at RIM, bringing in outsiders and eliminating approximately onethird of the workforce was not enough to shake its established norms.

Leadership has taken on a significant role in today's competitive environment. It has taken on an even greater role in corporate entrepreneurship. Leadership can have a significant impact on what gets done in the corporation. Any model for corporate entrepreneurship should include: support from upper management (particularly the CEO), exclusive of direction; and tolerance of risk or even failure by the corporation. Research supports the importance of utilizing these in undertaking entrepreneurial efforts.

In terms of leadership, there is no shortage of opinions on whether a new CEO is needed, especially when a firm's survival is threatened. Mired and pulled in a myriad of directions, RIM has struggled with this issue. Should it hire someone from outside of the firm to re-energize the organization. Roger Martin, a RIM board member, pointed out that Dell, HP, and Apple turned to outsiders for CEOs but admits they failed miserably. On the subject of an external candidate to fill the CEO's shoes, Martin remarked "So we're supposed to hand it over to children, or morons from the outside who will destroy the company?" When co-CEOs Balsillie and Lazaridis stepped down, their continuing presence as directors raised concerns that new CEO Heins might not be able to chart an independent course (Pitts, 2012). The two company builders eventually pulled back further.

Research by Karaevli and Zajac (2012, p. 15) finds that boards often hire external CEOs to "lead their companies through major transformations" but do not retain them after this period. Their data indicate that external CEOs outperformed insiders when the company had a recent history of poor performance - such as the crisis at RIM. The rationale is that they bring fresh knowledge and a new perspective when a firm is at a crossroads. They are expected to stimulate change. They are "less tied up with internal political relationships [and] face fewer obstacles in pursuing the entrepreneurial decision making needed" (Karaevli and Zajac, 2012, p. 16). Poor corporate performance makes it easier for a new CEO to overcome internal resistance to new initiatives (Karaevli and Zajac, 2012, p. 16). External CEOs outperform insider successors "when they replace the company's senior management team with new executives" (Karaevli and Zajac, 2012, p. 15). Seeming to follow this wisdom, RIM also took the step of installing a new top management team.

Summary statements about RIM are on target: "having grown too big too fast, maybe now it'll reconsider how it manages resources. Adversity is an opportunity... they need to turn their challenges into an Oprah moment 
that'll allow RIM to refocus" (Hicks, 2012). Miller and Burrows (2012) state, "Apple did many of the things RIM is attempting now: simplify the company, embrace a new operating system, and revamp the culture to focus on products that were true breakthroughs."

\section{CONCLUSION}

The age of globalized trade and communications has taken competition to new levels. The result is new challenges for mature corporations in what were established markets. New competitors, markets, and practices have made an entrepreneurial orientation essential to growth and long-term survival in the globalized world (Kurtatko et al., 2015). We concur with Jones $(2004$, p. 1268) that globalization "challenges the influence of national borders and laws, breaks down artificial barriers in the marketplace, and extends the abilities of individuals to communicate, acquire knowledge, compare options and make choices" the divisions between established and new competitors are eroded (Jones, 2004, p. 1268). According to Marger (2001), it can be inferred that this clash between the established culture and the outsider culture is what drives the dynamism of entrepreneurship and results in the creation of new markets, products, and processes.

Being at the cusp of this tension, the entrepreneur who operates without regard to the institutions, practices, and culture of the established marketplace exemplifies how being on the margin can be a benefit (Cliff et al., 2006). Corporations can internalize this dynamism (Marger, 2001) by engaging in endeavors that evade existing processes, values, and resource bases in order to satisfy the demands of new markets that are not yet attractive to the established firm/industry. Lévesque and Shepherd (2004, p. 35) present a model of entrepreneurial entry strategy in terms of entry timing and level of mimicry as "the degree to which new ventures imitate the key practices of others." Following the orthodoxy of the pack with a 'me too' strategy, however, is in stark contrast to the outsider perspective that portrays entrepreneurial efforts designed to exploit a fresh idea.

Block and MacMillan (1993), Lerner et al. (2007), and others demonstrates that strict adherence to corporate institutions (rooted in a firm's processes, values, and resources) can inhibit entrepreneurial activity. The hallmarks of the most prolific innovators in modern industry, such as Hewlett-Packard, have been informality, decentralization, inclusiveness, and other such values that enable the sharing and implementation of diverse 
perspectives (Leslie, 2000). Not surprisingly, some scholars have used the words diversification (Burgelman, 1983) and renewal (Stopford, 1994) to describe the process of corporate entrepreneurship. Both these words imply a departure from established processes, values, and resources.

We have proposed that an outsider perspective - learning to think like an outsider - can provide innovation and improve the corporation's chances of growth and success. The benefits of taking this perspective are numerous. Corporate entrepreneurship has been recognized as a "means for promoting and sustaining corporate competitiveness" and "improving the competitive positioning" of existing firms (Covin and Miles, 1999, p. 47). Tang and Rothenberg (2009, p. 79) indicate "entrepreneurs are often leading or even causing environmental changes, and thus they may perceive greater industrial instability than there actually is." This "creative destruction' is the root of all innovation and entrepreneurship. Like fire, it has the ability to be destructive or lead to renewal of the corporate landscape (Rogoff and Heck, 2003, p. 559). This process erases barriers to free and fair competition (Porter, 1998) and results in supplanting inferior processes, values, and resource bases in favor of better adapted ones. Companies that wish to remain at the threshold of innovation must approach problems without regard to existing corporate processes, values, and resource bases. Indeed, corporate entrepreneurship is only possible when an established firm begins to think like an outsider.

\section{References}

Baumol, W. J. (1993). Entrepreneurship, Management, and the Structure of Payoffs. Cambridge, MA: MIT Press.

Block, Z. and MacMillan, I. C. (1993). Corporate Venturing: Creating New Businesses within the Firm. Boston, MA: Harvard Business School Press.

Burgelman, R. A. (1983). Corporate entrepreneurship and strategic management: Insights from a process study. Management Science, 29(12):1349-1364.

Chowdhury, S. (2005). Demographic diversity for building an effective entrepreneurial team: Is it important. Journal of Business Venturing, 20(6):727-746.

Christensen, C. M. and Overdorf, M. (2000). Meeting the challenge of disruptive change. Harvard Business Review, 78(2):67-76.

Cliff, J. E., Jennings, P. D. and Greenwood, R. (2006). New to the game and questioning the rules: The experiences and beliefs of founders who start imitative versus innovative firms. Journal of Business Venturing, 21(5):633-663.

CNET (2011). "How RIM intends to light a fire under developers" November 14. http:// www.cnet.com/news/how-rim-intends-to-light-a-fire-under-developers/ 
Covin, J. G. and Miles, M. P. (1999). Corporate entrepreneurship and the pursuit of competitive advantage. Entrepreneurship Theory \& Practice, 23(3):47-63.

Covin, J. G. and Slevin, D. P. (2002). A conceptual model of entrepreneurship as firm behavior. In N. Krueger (ed.) Firm-Level Entrepreneurship. London, UK: Routledge.

Covin, J. G., Slevin, D. P. and Heeley, M. B. (2000). Pioneers and followers: Competitive tactics, environment, and firm growth. Journal of Business Venturing, 15(2):175-210.

Engelen, E. (2001). 'Breaking in' and 'breaking out': A Weberian approach to entrepreneurial opportunities. Journal of Ethnic and Migration Studies, 27(2):203-223.

Ensign, P. C. and Robinson, N. P. (2008). BlackBerry in red China: Research In Motion navigates institutional barriers in an emerging market. Thunderbird International Business Review, 50(2):129-139.

Ensign, P. C. (2009). Knowledge Sharing Among Scientists: Why Reputation Matters for $R \& D$ in Multinational Firms. New York, NY: Palgrave Macmillan.

Evald, M. R. and Senderovitz, M. (2013). Exploring internal corporate venturing in SMEs: Effectuation as work in a new context. Journal of Enterprising Culture, 21(3):275-299.

Ferreira, J. (2002). Corporate Entrepreneurship: A Strategic and Structural Perspective. Paper presented at the International Council for Small Business Conference. San Juan, Puerto Rico.

Fillis, I. and Rentschler, R. (2010). The role of creativity in entrepreneurship. Journal of Enterprising Culture, 18(1):49-81.

Forbes (2015). Reinventing America: Manufacturing Innovation at Parker Hannifin, May 4, pp. 84-92.

Garrett R. P. Jr., and Covin, J. G. (2015). Internal corporate venture operations independence and performance: A knowledge-based perspective. Entrepreneurship Theory \& Practice, 39(4):763-790.

Gaw, A. and Lui, S. (2004). Corporate entrepreneurship: Beyond two guys in a garage. ESADE MBA Business Review, 2:67-69.

Gilbert, C. (2003). The disruption opportunity. Sloan Management Review, 44(4):27-32.

Hartopo, A. (2012). The downfall and demise of RIM. Jakarta Globe, 25 July.

Heinonen, J. and Toivonen, J. (2007). Approaching a deeper understanding of corporate entrepreneurship - Focusing on co-evolutionary processes. Journal of Enterprising Culture, 15(2):165-186.

Hicks, J. (2012). High and low: What RIM's failure is doing to the people of Waterloo. The Verge, 1 August.

Jones, S. (2004). Canada and the globalized immigrant. American Behavioral Scientist, 47 (10):1263-1277.

Karaevli, A. and Zajac, E. J. (2012). When is an outsider CEO a good choice. Sloan Management Review, 53(4):15-17.

Kelmar, J. H. (1994). Ethnic enclaves and small business ownership patterns in Western Australia. Journal of Enterprising Culture, 2(3):883-855.

Kuratko, D. F. and Audretsch, D. B. (2013). Clarifying the domains of corporate entrepreneurship. Internal Entrepreneurship Management Journal, 9(3):323-335.

Kuratko, D. F., Covin, J. G. and Hornsby, J. S. (2014). Why implementing corporate innovation is so difficult. Business Horizons, 57(5):647-655. 
Kuratko, D. F., Hornsby, J. S. and Covin, J. G. (2014). Diagnosing a firm's internal environment for corporate entrepreneurship. Business Horizons, 57(1):37-47.

Kurtatko, D. F., Hornsby, J. S. and Hayton, J. (2015). Corporate entrepreneurship: The innovative challenge for a new global economic reality. Small Business Economics, 45(2):245-253.

Lassen, A. H. and Nielsen, S. L. (2009). Corporate entrepreneurship: Innovation at the intersection between creative destruction and controlled adaptation. Journal of Enterprising Culture, 17(2):181-199.

Leslie, S. W. (2000). The biggest "angel" of them all: The military and the making of Silicon Valley. In M. Kenney (ed.) Understanding Silicon Valley: The Anatomy of an Entrepreneurial Region. Stanford, CA: Stanford University Press.

Ley, D. (2006). Explaining variations in business performance among immigrant entrepreneurs in Canada. Journal of Ethnic and Migration Studies, 32(5):743-764.

Lerner, M., Zahra, S. A. and Kohavi, Y. G. (2007). Time and corporate entrepreneurship. In G. T. Lumpkin and J. A. Katz (eds.) Advances in Entrepreneurship, Firm Emergence and Growth. London, UK: Elsevier.

Lévesque, M. and Shepherd, D. (2004). Entrepreneurs' choice of entry strategy in emerging and developed markets. Journal of Business Venturing, 19(1):29-54.

Lumpkin, G. T. and Dess, G. G. (1996). Clarifying the entrepreneurial orientation construct and linking it to performance. Academy of Management Review, 21(1):135-172.

March, J. G. (1995). The future disposable organizations and the rigidities of imagination. Organization, 2(3/4):427-440.

Marger, M. N. (2001). Social and human capital in immigrant adaptation: The case of Canadian business immigrants. Journal of Socioeconomics, 30(2):169-170.

Miller, D. (1983). The correlates of entrepreneurship in three types of firms. Management Science, 29(7):770-791.

Miller, H. and Burrows, P. (2012). Apple provides lessons for RIM's BlackBerry comeback. Bloomberg, 27 July.

Ozgen, E. and Baron, R. A. (2007). Social sources of information in opportunity recognition: Effects of mentors, industry networks, and professional forums. Journal of Business Venturing, 22(2):174-192.

Penrose, E. T. (1959/1995). The Theory of the Growth of the Firm. Oxford, UK: Oxford University Press.

Pittino, D. and Visintin, F. (2009). Innovation and strategic types of family SMEs: A test and extension of Miles and Snow's configurational model. Journal of Enterprising Culture, 17(2):257-295.

Pitts, G. (2012). Roger Martin: Defying RIM's critics. Globe and Mail, 24 February.

Porter, M. E. (1998). On Competition. Cambridge, MA: Harvard Business School Press.

Robinson, N. and Ensign, P. C. (2010). Transplanting the Meritocracy in India: Creating a Shared Corporate Vision at the Local and Global Levels in J. Syed and M. F. Özbilgin (eds.) Diversity Management in Asia: A Research Companion. pp. 330-351. London, England: Edward Elgar.

Rogoff, E. G. and Heck, R. K. Z. (2003). Evolving research in entrepreneurship and family business: Recognizing family as the oxygen that feeds the fire of entrepreneurship. Journal of Business Venturing, 18(5):559-566. 
Sathe, V. (2006). From surface to deep corporate entrepreneurship. Human Resource Management, 27(4):389-411.

Scallan, N. (2012). RIM's corporate culture could be toughest battle for new hires. Toronto Star, 9 May.

Stopford, J. M. (1994). Creating corporate entrepreneurship. Strategic Management Journal, 15(10):521-536.

Strom, D. (2011). Top ten signs you need to retool your business October 4, http:// readwrite.com/2011/10/04/top-10-signs-you-need-to-retoo.

Tang, Z. and Rothenberg, S. (2009). Does perceptual acuity matter? - An investigation of entrepreneurial orientation, perceptual acuity, and firm performance. Journal of Enterprising Culture, 17(1):79-102.

Taylor, B. (2001). From corporate governance to corporate entrepreneurship. Journal of Change Management, 2(2):128-147.

Timmons, J. A., Spinelli, S. and Ensign, P. C. (2010). New Venture Creation: Entrepreneurship for the 21st Century. McGraw-Hill.

Turró, A., Urbano, D. and Peris-Ortiz, M. (2014). Culture and innovation: The moderating effect of cultural values on corporate entrepreneurship. Technological Forecasting \& Social Change, 88:360-369.

Weiblen, T. and Chesbrough, H. W. (2015). Engaging with startups to enhance corporate innovation. California Management Review, 57(2):66-90.

Zahra, S. A. and Covin, J. G. (1995). Contextual influences on the corporate entrepreneurship-performance relationship: A longitudinal analysis. Journal of Business Venturing, 10(1):43-58.

Zahra, S. A. (1991). Predictors and financial outcomes of corporate entrepreneurship: An exploratory study. Journal of Business Venturing, 6(4):259-285.

Zahra, S. A. (1993). Environment, corporate entrepreneurship, and financial performance: A taxonomic approach. Journal of Business Venturing, 8(4):319-340.

Zhu, H., Hitt, M. A. and Tihanyi, L. (2007). The internationalization of SMEs in emerging economies: Institutional embeddedness and absorptive capacities. Journal of Small Business Strategy, 17(2):1-26. 